\title{
The affordances of screen capture technology for retrospective analysis of the writing process
}

\author{
Sabbaghan, Soroush $\measuredangle$ \\ Islamic Azad University, Science and Research Branch, Iran (ssabbagh@ucalgary.ca) \\ Maftoon, Parviz \\ Islamic Azad University, Science and Research Branch, Iran (pmaftoon@srbiau.ac.ir)
}

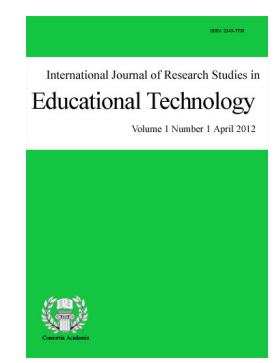

ISSN: 2243-7738 Online ISSN: 2243-7746 DOI: $10.5861 /$ ijrset.2015.984

Accepted: 16 December 2014

OPEN ACCESS

\section{Abstract}

Screen recording technology provides us with means of analyzing the writing process. However, the possible advantages of using retrospective protocols with this new technology have not been explored. This paper investigated how stimulated recall induced peer-peer and instructor-student interactions during the replay of the participants' writing process using screen recording software affected the number of surface and non-surface changes made either during (noticing) or after (revision) the stimulated recall session (SRS). Twenty skilled users of English wrote different argumentative essays and recorded the writing process. Next, they participated in SRSs while watching the replay of their writing process, three times with a peer (twice as practice) and once with an instructor. Modifications were made during and after the SRSs. The results indicate that the number of modifications made in the instructor-student SRSs were greater than in peer-peer SRSs. However, further analysis revealed that the participants made more non-surface changes in instructor-student SRSs than in peer-peer SRSs. Intriguingly, no significant difference was found in the number of surface changes between the two types of SRSs. Implications of the finding are further explored.

Keywords: screen capture technology; stimulated recall; writing process; noticing; revision 


\section{The affordances of screen capture technology for retrospective analysis of the writing process}

\section{Introduction}

In the ELS/EFL contexts, computers have generally been regarded as writing instruments. More recently, however, they have been used as hosts for digital pedagogical instruments designed to provide fine-grained analysis of emerging writing processes. For example, software can be specifically adjusted to make observations of students' actions during the writing process on their computers (Barbier \& Spinelli-Jullien, 2009). Some of these software that have been instruments in recent research studies include key-stroke logging (Miller, Lindgren, \& Sullivan, 2008; Spelman Miller, 2005), eye tracking (Wengelin et al., 2009), juxtaposition of keyboard of on-screen events (Van Waes \& Leijten, 2006; Van Waes, Leijten, \& Van Weijen, 2009), and screen capture of events and processes (Geisler \& Slattery, 2007; Seror, 2013; Silva, 2012).

With the emergence of these new technologies, educators now have the opportunity to change the manner in which they respond or provide feedback to students' writing. For instance, the instructor may choose to create a feedback video for the composition. Newer versions of this software can record a teacher's voice while recording screen movements. Elements of the composition such as a single word, phrases, sentences, or paragraphs can be highlighted during feedback recording. The instructor may choose to provide references on specific topics by providing or opening web links, which offers another layer of visual feedback. In addition, general computer tools such as email or video conferencing are used to in peer review of the writing. Some have identified the advantage of using such tools as providing students with opportunities to offer reviews for their peers' writing across academic and professions contexts (Goldin, Ashley, \& Schunn, 2012). While these reviews may highlight specific area needing further attention, the reviews themselves can provide instructors with insights into the reviewers' understanding of writing.

Screen-capture software has generated interests among scholars as it uncovered interesting affordances. The studies that have used screen-capture software for feedback purposes suggest that it can be quite a valuable instrument. For example, Stannard (2008) used screen-recording software to provide a video commentary of the revisions made on student compositions. The advantage of this kind of feedback was that students could see and hear their instructor reviewing their compositions. The students had the opportunity to pause and repeat the video as much as they needed to and as often as they preferred. Stannard (2008) further reported that feedback from students receiving video feedback was very positive and that students preferred video feedback to traditional forms involving marking and written comments. Silva (2012) examined students' perceptions and attitudes toward written and visual/audio feedback via screen-capture software. She reported that students who prefer visual/audio feedback seem to notice more global aspects, while students who preferred written comments highlighted more surface errors, and issues at the local level. Other studies further provide evidence that students seem to prefer video feedback to written feedback and face-to-face conferences (Siegel, 2006).

In addition to enhancing the feedback given to the product of students' writing, screen capture programs can also be used to provide feedback on students' writing process. This can be accomplished when students are invited to write a composition, during which, anything visible on the computer monitor (i.e., editing, revising, researching, and etc.) is recorded by screen capture software. Seror (2013) used these videos to explore the strategies students employed and the behaviors they displayed during the writing process. Reviewing these videos can potentially be educational as they can reveal nuances in the writing process that other forms of observation might not be able to do. The review can be conducted with both the student and the instructor as participants in a private session. The advantage of such reviews, as indicated by Moore and Filling (2012) is that the feedback provided tends to be detailed and tailored to each individual student. Another benefit of conducting an instructor-student face-to-face session while watching the video is that any miscommunication that might 
The affordances of screen capture technology for retrospective analysis of the writing process

occur via written comments could be avoided. In these sessions, the instructor would have an opportunity to provide feedback and respond to questions and perspectives that the student may have, which can improve writing efficiency (Beach, 1989; Frank, 2001; Lerner, 2005).

Face-to-face sessions, however, have some drawbacks. For instance, Carabajal, LaPointe, and Gunawardena (2003) found that students feel more comfortable in online conference session than in face-to-face sessions because of the perceived distance. They also found that instructors feel less social pressure in online sessions to be accurate, articulate, and adept at commenting. Their findings also indicates that in face-to-face sessions, instructors are also more inclined to be conscious of body language and social cues, not to mention emotions. Warnock (2008) found that student prefer face-to-face sessions over online conferencing, but prefer online conferencing to traditional written feedback on their writing. Therefore, it seems that optimal conditions for interaction require conducting face-to-face sessions that include multi-sensory feedback.

Instead of providing direct feedback, another way on conducting instructor-student face-to-face sessions would be to have the instructor employ consciences-raising measure so as to alert the student's attention to changes required to improve the composition. Furthermore, watching the writing process could afford new possibilities for the students to make improvements on their texts. Lindgren and Sullivan (2003) conducted face-to-face sessions with participants using key stroke logging and found that replaying a writing event using key stroke logging in real time in collaborative reflective sessions (via stimulated recall) allow the students to reflect on and evaluate their thoughts and actions that transpired while writing. Their findings suggest that through collaborative reflective sessions, learners may notice features in their writing process of which they had been previously unaware. Furthermore, the experience may trigger increases in metaconscious awareness levels regarding their writing process, and lead students to realize the appropriate changes they would need to make on the procedures that they currently employ in their writing process in order to enhance their writing abilities. These modifications cannot be gained by ex post facto feedback that is currently dominant in writing classes.

Conducting face-to-face sessions often have feasibility issues as the instructor might not be able to find the time to conduct several feedback sessions for every member of his or her class. One solution to this problem would be to invite students to watch drafting videos together and provide each other with feedback. However, it could be argued that the feedback the instructor provides is more comprehensive then feedback specified by peers. Sabbaghan (2013) conducted a study using InputLog as the instrument for reviewing writing process during collaborative reflective face-to-face sessions. Two types of sessions were carried out, one was guided by instructor, and other sessions were peer-peer feedback sessions. The results indicated that the face-to-face sessions with an instructor produced more revisions by the participants at the global level (e.g. adding/removing sentences, changing theme, restructuring paragraphs). However, no significant difference for surface changes (e.g. grammar, spelling, punctuation) was found between the two session types.

In essence providing feedback is an awareness raising activity. One of the goals of delivering feedback is so that students "become aware of and able to control the processes involved in writing" (Lindgren, 2004, p. 260). However, there are other elements that affect students' writing ability. For example, good writers are able in producing “...fluent text-generating and transcription processes" and they need to have "...extensive knowledge about topics, text genre, and routines for coordinating writing processes” (McCutchen, 2000, p. 15). Young and novice writers might not always have these abilities and often they translate their thoughts into written text. Furthermore, their lack of knowledge and experience often limits their revisions to mostly surface level changes (Lindgren, 2004). In other words, students' ability to simultaneously consider both linguistic and content demands, particularly in a second language, is subject to the limitations in working memory capacity (McCutchen, 1996, 2000). A constrained cognitive capacity could force the writer to focus attention on certain aspects, such as spelling and punctuation, while other aspects (e.g. planning) are left in the background. The findings of some studies indicate that reducing the cognitive load during writing may contribute to improving the writing ability (Braaksma, Rijlaarsdam, \& Van den Bergh, 2002; Braaksma, van den Bergh, Rijlaarsdam, \& Couzijn, 2001). In these studies, the students watched the writing process of their peers, and they were able to 
focus more on global level aspects on the composition compared to reviewing a composition that they had written themselves.

Inherently, the reduction in cognitive load augments the possibility for writers to widen their focus of attention, which would in turn increase the probability of noticing feature in the writing process. Students' ability to notice is instrumental in becoming proficient in L2 writing (Adams, 2003; Hanaoka, 2007; Qi \& Lapkin, 2001; Swain \& Lapkin, 1995). One method that may afford more noticing is to "...offer student the opportunity to 'step out' of the writing process on order to observe their activities and results, and learn from this by verbalizing what they observe" (Rijlaarsdam \& Couzijn, 2000, p. 176). This claim is supported by theoretical framework proposed by (Vygotsky, 1998), who believed that social interaction and collaboration, which includes verbalization, are fundamental elements of a learning situation.

Even when cognitive recourses are readily available, what students will notice in their writing (product or process) depends on the level of input primed for the individual learner. Observational learning, for example, has been demonstrated to be more effective when the students observe models of writing at the same language competency level as their own proficiency level (Braaksma et al., 2002; Braaksma et al., 2001). However, finding the right level of writing input for each learner can be very challenging. (Rijlaarsdam \& Couzijn, 2000) believe that using one's own writing process would provide input at the right competency level, and therefore, advocate that one's own writing output can be used as input for learning. If learners can verbalize their writing process, at the time they were writing, coupled with social interaction, they would be essentially targeting their own zone of proximal development, and hence increase the odds of improving their writing ability.

Research (Lindgren \& Sullivan, 2003; Sabbaghan, 2013) has suggested that replay of the production process in collaboration with in-depth discussion - achieved via stimulated recall (Gass \& Mackey, 2013) - of the writing event can trigger noticing and increase language awareness levels. Their finding also suggest that using stimulated recall may lead to more surface changes (e.g. changes of spelling, grammar, punctuation) and non-surface changes (i.e. change of content at a local and/or global level) on a text. However, the combination of using screen recording technology and stimulated recall for learners' own on-line output, used as input to increase noticing instances as well as various writing features (both at the local and global level) has not been conducted.

The present study was conducted to compare the number and types of modifications made to a text written by the students with the replay of the composition process during peer-peer and instructor-student stimulated recall sessions (SRS). Modifications was operationalized as the surface and non-surface changes made either during (henceforth noticing) or after (henceforth revision) the stimulated recall sessions. The study attempted to explore the following research questions:

$>$ Is there any significant difference between occurrences of noticing and revisions?

$>$ Does conducting a stimulated recall session with a peer, as opposed to conducting it with an instructor affect the number of modifications in the text?

$>$ Does conducting a stimulated recall session with a peer, as opposed to conducting it with an instructor affect the type of modification in the text?

\section{Method}

\subsection{Participants}

The participants in this study were Iranian EFL student-teachers, who volunteered to be part of the study. Their age ranged from 21 to 25 . They were participating in a four-week teacher-training course as a requirement for employment. The minimum language proficiency requirement for participation was an overall band score of 
The affordances of screen capture technology for retrospective analysis of the writing process

7 on the IELTS, although eight participants had obtained an overall band score of 7.5. There were 20 participants in total - consisting of five males and 15 females. Participants had either a bachelor's degree in TESOL or English translation or were in their senior year of these majors. The participants were informed that partaking in the study required basic knowledge of MS Word and the ability to type relatively well.

\subsection{Materials and instruments}

Camtasia is a screen-capture software that records all screen movement and activities (e.g., typing in a word-processing application, surfing the Internet, and etc.). It was selected because of one of the researcher's previous experience using the software and that two licenses had already purchased for other studies. The advantage of Camtesia over key stroke-logging software is that it gives control the user. For example, using Camtasia requires the software to be opened and set to record manually. There is also a choice for recording a portion of the screen, which allows users some privacy. When the record button is clicked, a small red circle indicating that recoding is in process in the Windows toolbar appears. Recording can be paused, which is ideal for students who wish to stop for any reason during the writing process. Once the writing has been completed and the recording function has been stopped, the user has the option to save the recording in a format, which can only be opened with Camtasia. In the study, Camtesia for Windows was installed on 5 laptop computers (other licenses were purchased), as often the SRSs occurred simultaneously.

The participants were given four argumentative topics (see Appendix A) because all of them had previously taken the IELTS and were familiar with the structure of an argumentative essay. With the exception the first topic, which was a controversial issue at the time of conducting research, the other three topics were selected because they were related to educational issues. Topic 1 and Topic 2 were used in the practice SRSs between peers, Topic 3 was selected for actual data gathering in peer-peer SRSs, and Topic 4 was chosen for the instructor-student SRSs, where data for the study was collected. Moreover, a handout containing instructions, and the dates and times for the SRSs was given to participants.

\subsection{Procedure}

In a briefing session, all participants were informed of the aims, procedures, and requirements of the research. The principles and protocol of conducting a SRS was explained based on the framework provide by (Gass \& Mackey, 2013). The participants were informed that the study would be conducted in two phases. In Phase One, the participants would engage in two practice SRSs with each other and receive feedback from one of the researchers. In Phase Two, two SRSs would be conducted for each participant; once with a peer, and once with an instructor (one of the authors of this paper). Data for the study was collected in the SRSs in Phase Two. A separate time schedule for each of the two phases was created for the participants and given to them in the briefing session.

\section{Phase one}

In Phase One, on the first day of writing, 10 participants were randomly selected and instructed to write an argumentative essay for the first topic in 40 minutes; which is the same time constraint imposed by the IELTS. This process was repeated for the second half of the participant and the second day. The writing session took place after the teacher training class on one of the laptops, which had Camtesia installed, in the training center. They were instructed to use MS Word when writing, which was reconfigured so that the auto correct function as well as all proofreading functions were deactivated. Making these setting changes was necessary because one of the areas of focus in the study was tracking instances of surface changes, which would have been severely limited if these function were activate. The participants were instructed to press record before beginning the writing process, and save the video file when they were done, or 40 minutes was completed.

After all the essays for the first topic were recorded (on the third day), the participants were randomly paired with a peer for a practice SRS. Each participant took turns being the recaller. A modified protocol for stimulated 
Sabbaghan, S., \& Maftoon, P.

recall (see Appendix B) proposed by (Mackey, Gass, \& McDonough, 2000) was used to begin the sessions. All sessions were audio recorded. The recaller was told that he or she is going to watch the video of the writing process of the essay that he or she had written. They were also told that they were going to discuss what the recaller was thinking at the time he or she was writing. The recaller was told that he or she was allowed to pause the video any time necessary. The other peer (the interlocutor), who was conducting the SRS, began the replay of the writing process. The interlocutor commentated on the replay of the text, and the recaller made remarks on what he or she was thinking at the time of writing. Two examples of these interactions are illustrated in Figure 1.

\author{
$1(a)$ \\ Interlocutor: OK, here you deleted "that" and the words after it. \\ Recaller: Yes, I thought the sentence was too long. \\ $1(b)$ \\ Interlocutor: Here, why did you add "foreign" before "language"? \\ Recaller: I thought if I write only "language" it referred to Persian.
}

Figure 1. Example of interlocutor recaller interaction

During the practice SRS sessions, the researchers monitored each pair to provide feedback on the interaction between the participants. Unfortunately, the researches were not able to sit through the entire peer-peer SRSs as there were always five simultaneous sessions being conducted. The feedback, some of which was given during the session and some after, focused on the interlocutor's comments and questions mainly on two areas. On many occasions, the monitoring researcher commented the interlocutor's ability to turn attention to the recaller's on-line thinking at the time of writing, as opposed to the recaller's current thinking on writing. Moreover, the researcher remarked on the statements the interlocutor used to lead the recaller to an answer. Examples of these interactions are displayed Figure 2.

2(a)

Interlocutor: ...their methods are not based on solid professional teaching techniques. That is true.

Recaller: Yes, I believe this.

Researcher: Saying "that is true" brings us to the here and now. Try to focus only on the time of writing.

Interlocutor: Here you realized that the spelling of "TOFFEL" was wrong, yes?

Recaller: Yes.

Researcher: A better question here would have been: What were you thinking when you saw TOFFEL?

Figure 2. Example of interlocutor, researcher, recaller interaction

The interlocutor was also asked not to comment on the legitimacy of any of the modifications the recaller mentions during the simulated recall session. An example of such an interaction is shown in Figure 3. 


\section{$3(a)$}

Interlocutor: There is a long pause here.

Recaller: Yes, I wasn't sure about this [last] sentence. But, I think, I'll change "the educational system has many errors" to "the educational system has many problems."

Interlocutor: $O K$.

Figure 3. Example of recaller and interlocutor interaction

All participants wrote two essays and participated in two practice SRSs. The recording and practice sessions lasted six days, as we could not conducted SRS continuously due to scheduling constraints. During this time, participants took turns becoming the interlocutor and the recaller twice.

\section{Phase two}

The procedure for Phase Two was very similar to that of Phase One. For peer-peer SRSs, half of the participants wrote their essays in the training center after class on one of the laptops, that had Camtasia installed. The SRS was conducted immediately after the essay was complete with the other half of the participants. These sessions were audio recorded and later transcribed. However, in these sessions, the researchers were not present. Additionally, the recaller was instructed to make revisions to his or her essay once the SRS was completed. The revisions were made on the MS Word file the recaller has previously written and this editing process was also recorded as saved as a separate video file.

When all the peer-peer SRSs were completed in Phase Two, the participants took part in a SRS with one of the researchers. Essays for the fourth topic were written in the institute after class on a Camtesia-installed laptop. The SRS was conducted immediately after each participant completed his or her essay. The procedure for the session was similar to the procedure in the peer-peer SRSs in Phase Two. The sessions were audio recorded, and later transcribed. After every session, the interlocutor asked the recaller to modify the essay on the MS Word file the recaller had written. The modification process was recorded with Camtesia and save as a video file. The researchers conducted one SRS per day. Taking into account the time required for the peer-peer SRSs, the data gathering process for Phase two lasted two weeks.

\subsection{Data analysis}

The transcriptions of the audio recorded sessions and the video recordings of revisions made after the SRSs in Phase Two were used to study the number and types of noticing instances and revisions made by the participants. The transcriptions of the audio recording of the SRSs were used to distinguish noticing instances from revisions. For example, if in the transcriptions there was a mention of removing an extra third person singular "s" from "wants" (an example of a surface change), and the change was implemented in the revision made after the SRS, then that change was labeled as noticing. Furthermore, if a participant mentioned that he or she wanted to make a change during the SRS but did not implement the change after the session, the citation was still construed as noticing. However, changes made after the SRS that were not mentioned in during the SRS were labeled as revisions.

Next, the modifications were categorized as either surface or non-surface changes. These categories were adopted from a study conducted by (Lindgren \& Sullivan, 2003). Surface changes include spelling, grammar, punctuation and meaning preserving-changes. In other words, these changes do not change the meaning of a clause, sentence, or paragraph. An example of a surface change can be observed in Table 1. 
Sabbaghan, S., \& Maftoon, P.

\section{Table 1}

Example of surface change

\begin{tabular}{ll}
\hline Writing replay & \multicolumn{1}{c}{ Stimulated recall comments } \\
\hline$\ldots$ they needs members from the new generation. & $\begin{array}{l}\text { Interlocutor: ... why is there a pause after } \\
\text { "generation"? } \\
\text { Recaller: I wasn't sure about "new generation." } \\
\text { Oh, there should be no "s" after need. }\end{array}$ \\
\hline
\end{tabular}

Non-surface changes affect the contents of the text. These changes affect the text at a local or global level. In other words, these changes alter the meaning a sentence or a paragraph, or change the overall theme of the text. An example of a non-surface change made during the SRS can be seen in in Table 2.

\section{Table 2}

Example of non-surface change during the session (noticing)

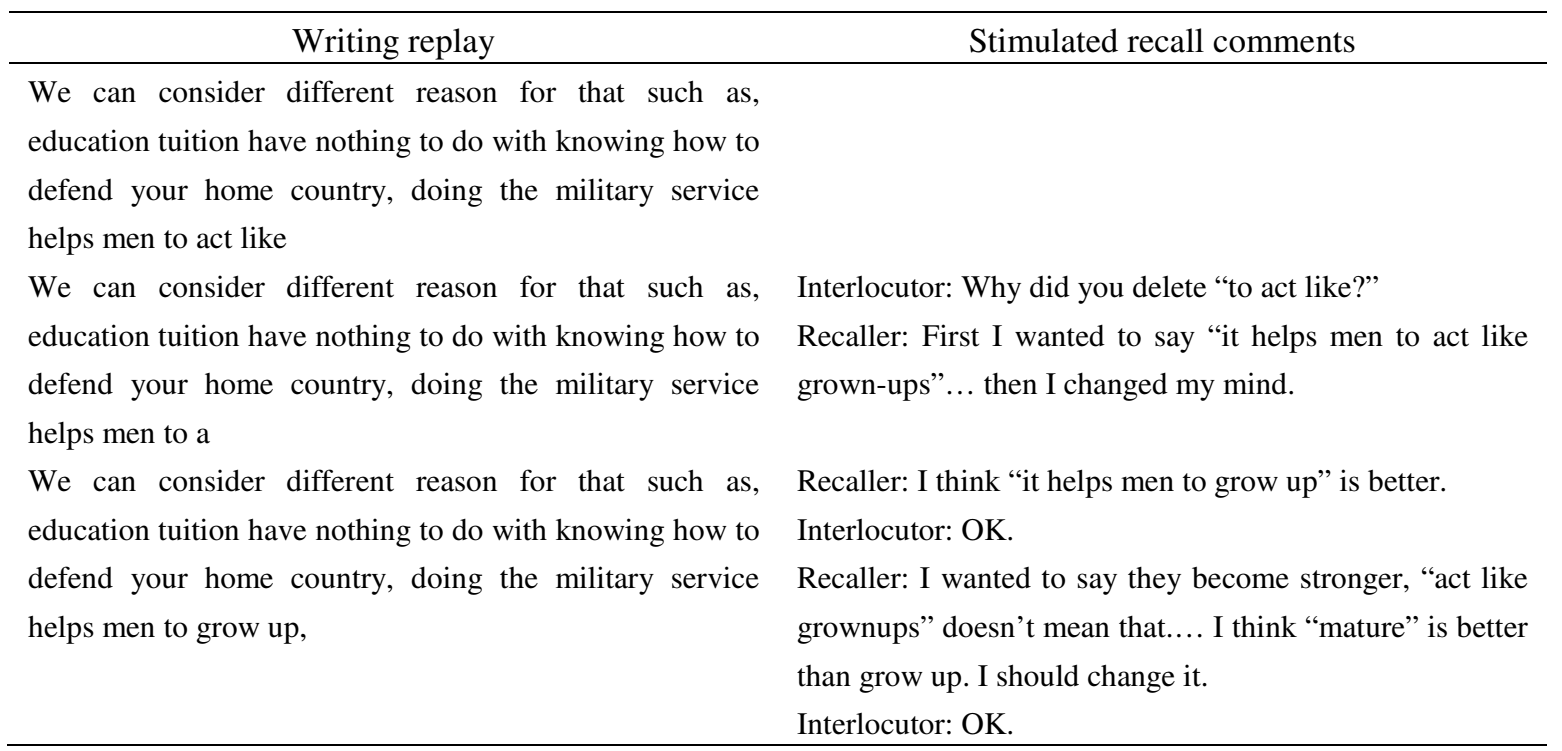

A sample of a non-surface change made after the SRS is provided in Table 3.

\section{Table 3}

Example non-surface change after the stimulated recall session (revision)

\begin{tabular}{|c|c|}
\hline Writing replay & Stimulated recall comments \\
\hline \multicolumn{2}{|l|}{$\begin{array}{l}\text { For example, two students from two different classes of a } \\
\text { society - one from the working class and another from the } \\
\text { middle class - fail the entrance examination and therefore } \\
\text { cannot attend any university. The wealthier one is able to } \\
\text { pay for university. }\end{array}$} \\
\hline $\begin{array}{l}\text { For example, two students from two different classes of a } \\
\text { society - one from the working class and another from the } \\
\text { middle class - fail the } \\
\text { Revision made after the session: }\end{array}$ & $\begin{array}{l}\text { Interlocutor: ... the wealthier one is able to pay for } \\
\text { university... there is pause here. } \\
\text { Recaller: Yes, I didn't think it was saying what I was thinking }\end{array}$ \\
\hline $\begin{array}{l}\text { For example, two students from two different classes of a sc } \\
\text { class - fail the entrance examination for university admissio } \\
\text { example going to another country to study. }\end{array}$ & $\begin{array}{l}\text { ciety - one from the working class and another from the middle } \\
\text { n. But the wealthier one is able to compensate this failure by for }\end{array}$ \\
\hline
\end{tabular}


Each researcher coded occurrences of noticing or revision separately. The categorizations were then compared and from a total of 771 labels (although initially the number of classifications was different for each researcher), 41 discrepancies were discovered. The opinion of a colleague, who had expertise in EFL writing, was sought concerning the inconsistencies, and after deliberation, the researchers agreed on the categorization of each disputed instance.

\section{Results}

Figure 4 provides a comparative illustration for the number and type of noticing instances and revisions in peer-peer and instructor-student SRSs.

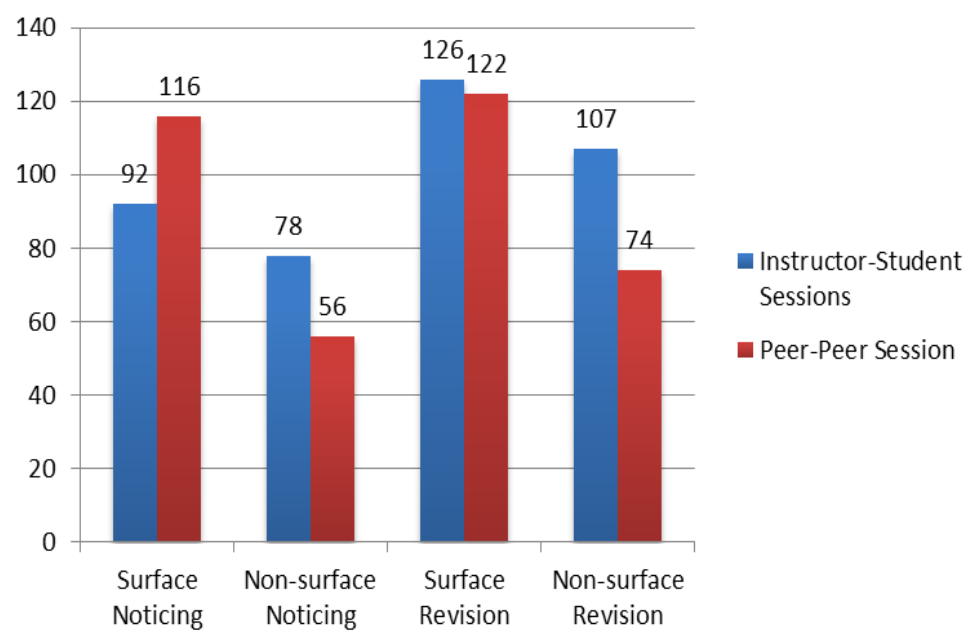

Figure 4. Comparison of modifications made to the text

According to data in Figure 4, the number of surface changes made during the peer-peer SRSs (noticing) was higher than those in the instructor-student SRS. However, the instances of non-surface change during the peer-peer SRSs (revision) were lower than those of instructor-student SRS. The number of revisions made to the texts was higher in both surface and non-surface changes in the instructor-student SRSs.

Two Mann-Whitney U Tests were conducted, as the data distributions of the modifications were not normal. The first test investigated whether of the number of modifications made in the instructor-student SRS was significantly different from the number of modifications made in the peer-peer SRS. The second test compared the number of noticing instances with the number of revisions. The results are displayed in Table 4.

\section{Table 4}

Results of the Mann-Whitney Test for modification comparison

\begin{tabular}{lccc}
\hline & Mann-Whitney & Z & Sig \\
\hline Instructor-student vs. Peer-peer & 9211 & -1.973 & 0.049 \\
Noticing vs. Revision & 7352 & -3.690 & 0.000 \\
\hline
\end{tabular}

The results in Table 4 show that there is a significant difference between the total number of modifications made in instructor-student SRSs and the peer-peer SRSs $(U=9211, p=0.049)$. Moreover, the analysis revealed a significant difference between the noticing instances and the number of revisions $(\mathrm{U}=7352, p=0.000)$.

Two Friedman tests were used to investigate whether the modifications made in the instructor-student and the peer-peer SRSs differ within groups. The results are displayed in Table 5. 
Sabbaghan, S., \& Maftoon, P.

\section{Table 5}

Results of the Friedman tests for within group comparisons

\begin{tabular}{lllll}
\hline & & Chi square & Sig \\
\hline Instructor-student & 3 & & 35.00 & 0.000 \\
Peer-Peer & 3 & 28.85 & 0.000 \\
\hline
\end{tabular}

The outcome of the tests indicate that there was a significant difference among the four types of modifications in the instructor-student $\operatorname{SRS}\left(\mathrm{X}_{(3)}^{2}=35.00, p=0.000\right)$. Moreover, there was a significant difference among the four types of changes applied by the participants in the peer-peer $\operatorname{SRS}\left(\mathrm{X}^{2}(\mathbf{3})=28.85, p=\right.$ $0.000)$.

Subsequently, Mann-Whitney U Tests were used to investigate whether data sets in the noticing and revision categories are statistically different from each other. A summary of the results is listed in Table 6.

Table 6

Results of Mann-Whiney U Tests comparing noticing and revision modifications

\begin{tabular}{|c|c|c|c|}
\hline & Pair & $Z$ & Sig \\
\hline \multirow{2}{*}{ Noticing } & Instructor-student vs. peer-peer surface changes & -1.386 & 0.166 \\
\hline & Instructor-student vs. peer-peer non-surface changes & -2.408 & 0.015 \\
\hline \multirow[t]{2}{*}{ Revision } & Instructor-student vs. peer-peer surface changes & -0.093 & 0.926 \\
\hline & Instructor-student vs. peer-peer non-surface changes & -2.896 & 0.004 \\
\hline
\end{tabular}

The findings indicate that there is no significant difference in the number of noticing instances for surface changes between the instructor-student and peer-peer SRSs $(U=-1.386 p=0.166)$. The same is also true for the amount of surface revisions $(U=-0.93 p=0.926)$. However, there is a significant difference in the number of modifications for both non-surface noticing $(U=-2.408 p=0.015)$ and non-surface revisions $(U=-2.863 p=$ 0.004 ) between instructor-student and peer-peer SRSs. In other words, it can be tentatively concluded that the participants made more non-surface changes in instructor-student SRSs then in the peer-peer SRSs.

\section{Discussion}

The results of different studies suggest that the combination of stimulated recall and replay of the writing process can cause an increase in language awareness, which may lead to making more text modifications (Lindgren \& Sullivan, 2003; Sabbaghan, 2013). However, these studies were small and used key-stroke logging software, which do not record all screen movement and activities. This limitation could hinder recall, and affect language awareness levels. The present study used Camtaisa to overcome this limitation in order to explore the elements that influence the type and number of modifications in SRSs while watching the replay of screen-captured recordings of the writing process. As the study is an attempt to uncover the possibilities for screen recording technology in ESL writing, and investigating the nature of modifications students implement is influenced by this technology, it is only natural to divide this discussion into two sections so that we may better reflect upon the purpose of the study.

\subsection{Nature of Modifications}

Indications of increases in language awareness are represented by instances of noticing and revisions in SRSs. The question of whether there is a difference in quantity between the two types of modifications was addressed in this study. The result of a Mann-Whitney Test (see Table 4) indicated that there was a significant difference between the two types of modifications, and based on the data in Figure 1, it can be cautiously assumed that SRSs yield more revisions than noticing instances. In the current study, $44 \%$ of all the modifications were made during the SRS, i.e. noticing, while $56 \%$ of the modifications were revisions. 
While the data shows more instances of revision, we should note that some of these instances might have been triggered during SRS sessions. In other words, the recaller might have made the decision to modify the text but also decided not to discuss it during the SRS, and therefore it would not have been labeled as noticing. In this study, out of the 771 modifications made to the texts, there were 429 instances of revision. However, we cannot be certain that the decision to make these changes was strictly made after the SRS sessions.

Another factor influencing a recaller's number and type of modifications is whether the interlocutor in SRSs is a peer or an instructor. The data in Figure 1 and Table 4 indicate that when the interlocutor was one of the researchers (instructor), modifications increased. These results are similar to the finding of (Paulus, 1999), which suggest non-surface level changes occur more often when an instructor in involved in their writing process. We could attribute increase in modifications to the high probability that recallers were more vigilant during SRSs with instructors due to social pressure. The results in Table 6 and Figure 1 support this claim as when the interlocutor is an instructor, the number of non-surface change increase. However, if heightened awareness is a key factor, it should increase all types of modifications. The data in Table 6 reveals that the number of surface modifications (noticing and revision) did not statistically increase when the instructor was the interlocutor. In other words, it seems that the number of instances in which students make spelling, grammatical, and punctuation changes is independent of who the interlocutor is during SRSs. Many of these changes were obvious typos, and therefore would have been seen regardless of who was the interlocutor in the SRSs. Therefore, the data seems to suggest that SRSs aid students in identifying otherwise inconspicuous ill-formed structures.

Exploring the characteristics of non-surface changes may reveal the elements required for student to make these modifications. First, we should mention that non-surface changes made to texts served a variety of purposes. Some of these changes clarified intent by means of adding information to a sentence or clause, while other sentences were completely and creatively restructured. For example, some of the non-surface changes involved changing the function of a statement from declarative to interrogative. There were instances of revisions that included the use of technical and academic vocabulary. In addition, some revisions demonstrated skilled use of literary devices, and there was one instance of the use of a pun.

Based on van Lier's model of language awareness, the awareness level required to make surface changes and non-surface modifications are different. According to van Lier, the awareness level required to make surface level modifications is defined as "a deliberate act of focusing attention, of noticing a linguistic feature"(van Lier, 2004, p. 100). However, a higher level of language awareness includes noticing plus "an element of playing with language and a manipulation of linguistic expression" (van Lier, 2004, p. 101). As mentioned before, many non-surface changes included manipulation of expression and "playing with language." Therefore, we believe that making non-surface level changes requires a higher level of language awareness than making surface level modifications.

When the interlocutor is an instructor, is it probable that the recaller attains higher level of language awareness. We speculate that this higher language awareness level is not achieved in the beginning of a SRS. The data in Table 6 and Figure 1 show that when the interlocutor was an instructor there is a significant increase in the number of non-surface modifications. One explanation of these results is that students in SRSs with an instructor achieve higher language awareness faster than when the interlocutor is a peer and so the recallers have more chances to either notice or reflect on non-surface modifications that may be applied after SRSs.

Students' perception of instructors as authorities figures could have influenced the results of this study. (Yang, Badger, \& Yu, 2006) suggest that students feel more compelled to make modifications when an instructor provides feedback. Although in this study, the instructor provided no feedback, the presence of an instructor in an SRS could have influenced students' assessment of their autonomy in selecting what they want to modify. In other words, students might have felt compelled to implement changes if they noticed or discussed them during an SRS. This might not have been the case in peer-peer SRSs. This possibility would again explain why the number of non-surface changes was higher in instructor-student SRSs. 
The results of the study indicate that the instructor as the interlocutor did not positively influence number of surface changes. Assuming that SRSs with an instructor raises language awareness levels, if surface level modifications were dependent of language awareness, we should have observed a statistical difference between peer and instructor SRSs both in the number of noticing and revision instances. The data, in Table 6 and Figure 1, however, indicate that there was more surface level noticing in peer-peer SRSs than the instructor-student SRSs. This may be due to students' reluctance to point out their mistakes in the presence an instructor. The data also shows no significant difference between the number of surface level revisions between peer-peer and instructor-student SRSs. These finding suggests that surface level noticing and revision are independent of language awareness levels. We believe that an important contributing factor in surface level modifications must be language proficiency as the student-teachers had obtained relatively the same IELTS scores. Evidently, according to Figure 1, the number of surface level noticing (116), and surface level revision (122) are very close, which suggests that a stagnant factor, such as language proficiency, has influence over implementation of modifications. The pedagogical implication of these findings is that peer-peer SRSs can be an excellent proofreading tool.

In the current study, the interlocutor of the peer-peer SRSs most certainly lacked expertise in conducting such sessions as they were all student-teachers, which could have had an impact on the number and type of modifications (Min, 2006). The transcriptions of these sessions reveal instances of misguided questions posed by the interlocutor, which might have interfered with the processes of noticing and revision. In addition, participants may have been uncomfortable discussing their own errors or pointing out the errors of others during the interactions. As a result, the recaller might have decided not to point out a noticed error, but then made the correction in the revision. Such instances would have been falsely labeled as revision. Therefore, there is a possibility that the number or revisions are not accurate. However, we believe that there were only few of these instances, and it is mostly likely that they did not have a significant impact on the result of the study.

\subsection{Screen Recording Technology}

There is little doubt that screen captures technology is potentially beneficial to both ESL writing research and pedagogy. We should note, however, that we regard this technology as being complementary to other traditional data sources and methodologies and together they can make significant contributions to the body of knowledge concerning ESL writing. Unraveling the intricacies involved in the writing process is complicated, and as indicated by (Torrance, van Waes, \& Galbraith, 2007), some scholars oversimplify the matter by assuming that writing is a homogenous whole. Screen capture technology can be used to detail the learning process and verify the importance of tools (e.g. spell checkers, dictionaries, thesauri, etc.) that could enhance writing. Furthermore, replay of the writing process provides the opportunity for writer to step back and review the process of their writing rather than solely focusing the product. This type of self-assessment was not possible before screen recording technology. Evaluating the writing process will likely put learner on the right path to make informed decisions to enhance their writing ability.

Screen recording technology can provide educators and learners with a wealth of information such as how they deal with errors (e.g. whether they correct themselves immediately or when revising) and how often and when they use resources (e.g. dictionaries, spell checks, etc.). This information could help students identify strength and weaknesses in writing strategies they use. It is becoming more evident that ESL writing is no longer a solitary process, as affordances of technology provide support in forms of scaffolded texts, resources, and voices of instructors and peers. This fundamental change in the way we write, will have a significant impact our pedagogy, and as indicated by (Grabill \& Pigg, 2010), the field will have to make appropriate adjustment to incorporate these evolving transformations.

The time it takes for a teacher to provide comments on a student's draft is approximately 40 minutes (Silva, 2012). All the peer-peer and instructor-students sessions lasted longer than the average. Therefore, conducting SRSs in the format presented in this study does not offer teachers time advantages. However, a combination of 
The affordances of screen capture technology for retrospective analysis of the writing process

different modalities of awareness raising strategies and providing feedback on both surface and non-surface level concerns may prove to become more effective and less time consuming. Instructors may even choose to select a mixed modality preferred by students, although chances are that initially students will select a means with which they are most familiar. That is why exposure to different language awareness raising strategies and feedback modalities are both necessary and potentially beneficial.

\section{Conclusion}

We believe that in addition to improving students' writing, another reason for incorporating technologies in ESL writing is to reduce the teachers' workload. In our experience, one of the reasons why ESL teachers are reluctant to do more writing tasks is due to the time burden often necessary to provide feedback to students' writing. If instructor-students SRSs focus on non-surface modifications and peer-peer SRSs focus on surface level changes, videos of the writing process can be played at faster speeds and therefore reducing the time required to provide feedback. Furthermore, by conducting peer-peer SRSs before instructor-student SRS, the student would not need to divide their attention and focus solely on global level issues in there writing.

Although there seems to be evidence that face-to-face instructor-student feedback sessions has precedence over other types of feedback (Lerner, 2005), conducting face-to-face sessions require a fixed schedule that may be inconvenient for both the instructor and the student. Other students and instructors have a full workload and planning feedback session for every student will inevitably become a scheduling nightmare. In order to decrease the workload, computer assisted writing (and reading) has been studied in an EFL context with promising results (Kazemzadeh \& Fard Kashani, 2013; Kim \& Kim, 2013). The advance of the instrumentation and the methodology used in the current study are the affordances they offer for distance learning education. SRSs can be conducted both within and outside the physical space of the classroom. Conducting SRSs in cyberspace will provide both students and instructors the luxury of flexibility that will accommodate different schedules, particularly for those students who can only allocate the weekends for further education. Furthermore, the replay of the recording of the changes students make to their writing can be used as pedagogical tool. These videos can be used in class or be accompanied by an audio commentary for online classes, in which, the instructor can explain the steps required to get from an average paper to an excellent paper.

It is important to point out that analyzing and interpreting data gathered from a replay of a writing process is difficult. One of the major limitations is the lack of taxonomies for analyzing such content. Furthermore, the aforesaid taxonomies need to take into account that the analysis of writing processes requires the evaluation of both introspective and retrospective data. Future research using replay of the writing process would be more accurate if the data gathered is combined with the facts obtained from other methods such as retrospective interview so that we can gain a deeper understanding into the rationalizations behind the writer's actions. Such combinations may provide a better understanding of the cognitive processes of writing, which are now argued to be abstract and reductive in nature.

The data retrieved from analyzing the replay of the writing process using Camtasia has the potential to produces a clearer and more accurate picture of the writing process for researchers and educators. This data can also be used stimulate students' retrospective account of their writing process, and increase awareness on their own writing. We believe that our role as ESL educators includes the pursuit of affordances that could potentially lead to more efficient pedagogical tools and enrich our understanding for second language learning. Exploring the applications of screen recording technology may be a tangent from current research in ESL writing, but it is a step towards improving accessibility of learning resources for language learners.

\section{References}

Adams, R. (2003). L2 output, reformulation and noticing: Implications for IL development. Language Teaching Research, 7(3), 347-376. http://dx.doi.org/10.1191/13621688031r127oa

Barbier, M.-L., \& Spinelli-Jullien, N. (2009). On-line tools for investigating writing strategies in L2. German as 
a Foreign Language, 2(3), 23-40.

Beach, R. (1989). Showing students how to assess: Demonstrating techniques for response in writing conferences. In C. M. Anson (Ed.), Writing and response: Theory, practice, and research. Urbana, IL: National Council of Teachers of English.

Braaksma, M. A., Rijlaarsdam, G., \& Van den Bergh, H. (2002). Observational learning and the effects of model-observer similarity. Journal of Educational Psychology, 94(2), 405. http://dx.doi.org/10.1037/0022-0663.94.2.405

Braaksma, M. A., van den Bergh, H., Rijlaarsdam, G., \& Couzijn, M. (2001). Effective learning activities in observation taks when learning to write and read argumentative texts. European Journal of Psychology of Education, 16(1), 33-48. http://dx.doi.org/10.1007/BF03172993

Carabajal, K., LaPointe, D., \& Gunawardena, C. N. (2003). Group development in online learning communities. In M. G. Moore \& W. G. Anderson (Eds.), Handbook of distance education (pp. 217-234). Mahwah, NJ: Erlbaum.

Frank, C. R. (2001). "What new things these words can do for you": A focus on one writing-project teacher and writing instruction. Journal of Literacy Research, 33(3), 467-506. http://dx.doi.org/10.1080/10862960109548120

Gass, S. M., \& Mackey, A. (2013). Stimulated recall methodology in second language research. Mahwah, NJ: Lawrence Erlbaum Assosicates.

Geisler, C., \& Slattery, S. (2007). Capturing the activity of digital writing. In H. A. M. D. N. DeVoss (Ed.), Digital writing research: Technologies, methodologies, and ethical issues (pp. 185-200). Cresskill, N.J.: Hampton Press.

Goldin, I. M., Ashley, K. D., \& Schunn, C. D. (2012). Redesigning educational peer review interactions using computer tools: An introduction. Journal of Writing Research, 4(2), 111-119.

Grabill, J., \& Pigg, S. (2010). The writing lives of college students. East Lansing, MI: Writing in Digital Environments Research Center.

Hanaoka, O. (2007). Output, noticing, and learning: An investigation into the role of spontaneous attention to form in a four-stage writing task. Language Teaching Research, 11(4), 459-479. http://dx.doi.org/10.1177/1362168807080963

Kazemzadeh, A. A., \& Fard Kashani, A. (2013). The effect of computer-assisted translation on L2 learners' mastery of writing. International Journal of Research Studies in Language Learning, 3(3). http://dx.doi.org/10.5861/ijrsll.2013.396

Kim, H., \& Kim, J. (2013). Reading from an LCD monitor versus paper: Teenagers' reading performance. International Journal of Research Studies in Educational Technology, 2(1), 1-10. http://dx.doi.org/10.5861/ijirset.2012.170

Lerner, N. (2005). The teacher-student writing conference and the desire for intimacy. College English, 68(2), 186-208. http://dx.doi.org/10.2307/30044673

Lindgren, E. (2004). The uptake of peer-based intervention in the writing classroom. In G. Rijlaarsdam, H. v. d. Bergh \& M. Couzijn (Eds.), Effective learning and teaching of writing (2nd ed., pp. 259-274). Dordrecht, The Netherlands: Springer.

Lindgren, E., \& Sullivan, K. P. (2003). Stimulated recall as a trigger for increasing noticing and language awareness in the L2 writing classroom: A case study of two young female writers. Language Awareness, 12(3-4), 172-186. http://dx.doi.org/10.1080/09658410308667075

Mackey, A., Gass, S., \& McDonough, K. (2000). How do learners perceive interactional feedback? Studies in Second Language Acquisition, 22(04), 471-497. http://dx.doi.org/10.1017/S0272263100004022

McCutchen, D. (1996). A capacity theory of writing: Working memory in composition. Educational Psychology Review, 8(3), 299-325. http://dx.doi.org/10.1007/BF01464076

McCutchen, D. (2000). Knowledge, processing, and working memory: Implications for a theory of writing. Educational Psychologist, 35(1), 13-23. http://dx.doi.org/10.1207/S15326985EP3501_3

Miller, K. S., Lindgren, E., \& Sullivan, K. P. (2008). The psycholinguistic dimension in second language writing: Opportunities for research and pedagogy using computer keystroke logging. TESOL Quarterly, 42(3), 433-454.

Min, H.-T. (2006). The effects of trained peer review on EFL students' revision types and writing quality. Journal of Second Language Writing, 15(2), 118-141. http://dx.doi.org/10.1016/j.jslw.2006.01.003

Moore, N. S., \& Filling, M. L. (2012). iFeedback: Using video technology for improving student writing. Journal of College Literacy \& Learning, 38, 3-14.

Paulus, T. M. (1999). The effect of peer and teacher feedback on student writing. Journal of Second Language Writing, 8(3), 265-289. http://dx.doi.org/10.1016/S1060-3743(99)80117-9

Qi, D. S., \& Lapkin, S. (2001). Exploring the role of noticing in a three-stage second language writing task. 
The affordances of screen capture technology for retrospective analysis of the writing process

Journal of Second Language Writing, 10(4), 277-303. http://dx.doi.org/10.1016/S1060-3743(01)00046-7

Rijlaarsdam, G., \& Couzijn, M. (2000). What do writers learn from peer comments on argumentative texts. In G. Rijlaarsdam \& E. Espe'ret (Eds.), Studies in writing (Vol. 6, pp. 167-202). Amsterdam: Amsterdam University Press.

Sabbaghan, S. (2013). How noticing is affected by replay of writing process during stimulated recall. Procedia-Social and Behavioral Sciences, 83, 629-633. http://dx.doi.org/10.1016/j.sbspro.2013.06.119

Seror, J. (2013). Screen capture technology: A digital window into students' writing processes. Canadian Journal of Learning \& Technology, 39(3), 1-16.

Siegel, F. (2006). Scott Warnock, "Using Video Capture Software for Asynchronous A/V Writing Feedback." [Electronic Version]. CCCC 2006 Review, 3. Retrieved May 2, 2014, from http://wac.colostate.edu/atd/reviews/cccc2006/c24.cfm

Silva, M. L. (2012). Camtasia in the classroom: Student attitudes and preferences for video commentary or Microsoft Word comments during the revision process. Computers and Composition, 29(1), 1-22. http://dx.doi.org/10.1016/j.compcom.2011.12.001

Spelman Miller, K. (2005). Second language writing research and pedagogy: A role for computer logging? Computers and Composition, 22(3), 297-317. http://dx.doi.org/10.1016/j.compcom.2005.05.003

Stannard, R. (2008). Screen capture software for feedback in language education. Paper presented at the Second International Wireless Ready Symposium.

Swain, M., \& Lapkin, S. (1995). Problems in output and the cognitive processes they generate: A step towards second language learning. Applied Linguistics, 16(3), 371-391. http://dx.doi.org/10.1093/applin/16.3.371

Torrance, M., van Waes, L., \& Galbraith, D. (2007). Introduction. In M. Torrance, L. van Waes \& D. Galbraith (Eds.), Writing and cognition. Bingley, UK: Emerald Group Publishing Limited. http://dx.doi.org/10.1108/S1572-6304(2007)0000020002

van Lier, L. (2004). The ecology and semiotics of language learning: A sociocultural perspective (Vol. 3). Norwell, MA: Kluwer Academic Publishers. http://dx.doi.org/10.1007/1-4020-7912-5

Van Waes, L., \& Leijten, M. (2006). Logging writing processes with Inputlog. In M. L. L. Van Waes, C. M. Neuwirth \& G. Rijlaarsdam (Ed.), Writing and digital media (Vol. 17, pp. 158-166). Oxford, UK: Elsevier.

Van Waes, L., Leijten, M., \& Van Weijen, D. (2009). Keystroke logging in writing research: Observing writing processes with Inputlog. GFL-German as a Foreign Language, 2(3), 41-64.

Vygotsky, L. (1998). The problem of age. In R. W. Rieber (Ed.), Child psychology: The collected works of LS Vygotsky. New York: Plenum Press.

Warnock, S. (2008). Responding to student writing with audio-visual feedback. In M. A. C. Carter (Ed.), Writing and the iGeneration: Composition in the computer-mediated classroom (pp. 201-227). Southlake, TX: Fountainhead Press.

Wengelin, Å., Torrance, M., Holmqvist, K., Simpson, S., Galbraith, D., Johansson, V., et al. (2009). Combined eyetracking and keystroke-logging methods for studying cognitive processes in text production. Behavior Research Methods, 41(2), 337-351. http://dx.doi.org/10.3758/BRM.41.2.337

Yang, M., Badger, R., \& Yu, Z. (2006). A comparative study of peer and teacher feedback in a Chinese EFL writing class. Journal of Second Language Writing, 15(3), 179-200. http://dx.doi.org/10.1016/j.jslw.2006.09.004 


\section{Appendix A}

Topic 1 Men who pay for their education (school and university) should not be required to go to military service since their country did not pay for their education.

Topic 2 More and more people are relying on private institutes to learn English. Governments should adopt a language-teaching program similar to what institutes do in colleges and universities all over the country to promote the learning of English.

Topic 3 Some teachers believe that teaching English decreases their language proficiency because they spend a large portion of their time teaching lower levels, as they have to lower their level of language proficiency to be understood.

Topic 4 Some people believe that extra-curricular school activities are a waste of time. Children need to spend time studying books and doing homework. To what extent do you agree with this?

\section{Appendix B}

Protocol for a Stimulated Recall Session

Research responsibilities

$>$ Engage in some chitchat for about 1 or 2 minutes.

$>$ Give directions for the task.

$>$ Interact with participants during task activity.

$>$ Ensures that the session is being recorded.

Instructions before the session

"What we're going to do now is watch the video. I am interested in what you were thinking at the time you were writing this essay. I can see what you were doing by watching the recording, but I do not know what you are thinking. Therefore, what I would like you to do is tell me want you were thinking, what was in your mind at that time why you were writing the essay. You can stop the playback any time you want. So, if you want to tell me something about what you were thinking, you can press the pause button. If I have a question to ask you, then I will push the pause button." 